\title{
Students' perception of competences development in an undergraduate university environment
}

\author{
R. Gallo-Martínez*, M.C. Alarcón-del-Amo* \\ * Universitat Autònoma de Barcelona, Barcelona, Spain
}

\begin{abstract}
The pressure for universities to generate employable graduates requires the implementation of different ways of managing the learning process. Course programmes have thus been adapted to the new framework where skills and competences development are to be the resulting outcomes of students' stay at university. On-going evaluation systems, in combination with the selection of specific activities, help professors plan for the achievement of this objective. The study carried out in a group of $3^{\text {rd }}$ year Marketing students of Business and Management shows that students identify different activities as both adequate for and effective in competences development. The authors conclude that embedding competences development in course programming is a useful and helpful tool for course management that is well accepted and valued by students.
\end{abstract}

Keywords: Learning process; competences development; course programming

\section{Introduction}

Professionals at all levels of education, whether primary, secondary or terciary (higher) education, living in increasingly knowledge-based societies such as the European Union member countries, do not question the need to help students develop skills and competences allowing them to adequately enter the labor market (EACEA, 2014), which is to say, education, specially higher education, should increase graduates employability (EACEA, 2012).

However, employability is not only a necessary goal of higher education; it is also a “complex concept encompassing many definitions and approaches" (EACEA, 2014, p. 61). In fact, there seem to be two main approaches to help graduates achieve the adequate degree of employability: the employment-centred approach, which is related to increasing "graduates chances of finding employment soon after graduation" (EACEA, 2014, p. 63). Universities develop and implement programmes addressed towards helping students entry into the labor market; including practical training in study programmes, developing seminars about specific issues such as preparing C.V. and job interviews, creating placement offices, etc. (EACEA, 2014).

The other approach is the competences-centred one, where the role of higher education is "to develop the skills and competences of graduates necessary to find a job" (EACEA, 2014, p. 64), furthermore, "students' knowledge, skills and competences are expressed as the learning outcomes of the education process" (EACEA, 2010, p. 22). A learning outcome is understood to be a statement "of what a learner is expected to know, understand and/or be able to demonstrate at the end of a period of learning" (Adam, 2006), learning outcomes "chief advantage is the clarity and precision they bring to any curriculum development process” (Adam, 2006).

The competences-centred approach requires that education professionals, in this case higher/terciary education professors, understand their job to be student centred. Not a small challenge. According to the Eurydice Report: The European Higher Education Area in 2012 "genuine student-centred learning is (...) difficult to integrate into everyday higher education reality. It should comprise actions that ensure that students learn how to think critically, participate in all kinds of academic life and are given more 
independence and responsibility.” (EACEA, 2010, p. 25). The approach that can be found in Spain is this second one, the competences-centred approach. Although many Spanish Universities also implement employment-centred activities.

This article focuses on the analysis of students' perception of competences development and the adequacy of the tools used to help them develop these competences. This analysis was performed within a third year (junior) marketing course: Marketing I (Course 102353_04 Facultat d'Economia I Empresa, Universitat Autònoma de Barcelona -UAB).

The course program is designed according to an UAB model that is built on several assumptions, being one of them the fact that "competencies needed to be effective can be developed" (Boyatzis, 2008). Another one is that the "development of competencies needed to be effective managers and leaders require program design and teaching methods focused on learning” (Boyatzis, 2008).

\section{Course Programing}

The Marketing I course program includes, therefore, a list of 17 learning outcomes that can be organized into two categories, course specific and transversal learning outcomes, but can also be organized in the three categories established by Katz in 1974; technical skills, human skills and conceptual skills (Katz ,1974; Parente, 2012). These skills include analysis, critical thinking and problem solving (hard skills according to different authors (Parente, 2012)) as well as soft skills, related to dealing with others, such as communication skills and team work, information and knowledge sharing (Parente, 2012), as well as related to dealing with one-self, such as being able to organize one's learning process, time management, and information selection and generation among others.

Marketing I sessions were programed by the author-teacher with a "co-responsibitily" framework of mind. Both the professor and the student are responsible of the outcome of their interaction in Marketing I. The professor is to organize sessions' contents and activities in order to help students develop the learning outcomes of the course, and students are to invest the time, effort, as well as willingness and enthusiasm required for these learning outcomes to come true.

With this objective in mind both contents and activities were programmed. Activities include exercises, cases, articles and readings, oral presentations, and mind maps generation. Activities may be individual or in group, in order to help students develop competences related to dealing with others. Each type of activity is intended to help students develop specific competences, and may be to related more than one competence. Table 2 shows which competences are related to each type of activity.

Each activity was programmed at least twice during the course (15 weeks) in order for the learning process, usually cumulative, to take place. In that way students could incorporate the learning $s$ of the first time each activity was performed and see their own improvement the second time each activity was carried out.

\section{Methods}

The sample was composed by students enrolled on Marketing I UAB -ADE, English track $3^{\text {rd }}$ year. A total of 52 students were studied). Most of them were students from 
20 to 22 years old (82.7\%), 69.2\% female and 30.8\% male, both local (36.5\%) and Erasmus students (63.5\%).

The research instrument used in this research was a questionnaire that included personal characteristics, opinions, satisfaction and recommendation. Specifically a two-wave cross-section was conducted during the second semester of the academic course 201314.

The first wave was conducted at the beginning of the course asking questions about their expectations with regard the different activities that they will develop during the course and the objectives that they thought these activities would help achieve. Selfreport indicators of these expectations were measured by the items "Do you think these activities can help students achieve the objectives related to them?", to each activity and each objective. The questions had to be answered on a Liker scale ranging from strongly disagree (1) to strongly agree (5).

The second wave was conducted at the end of the semester, after completing the course, asking about their opinion with regard to the different activities and the objectives/capabilities that they had helped improve. This second questionnaire contained items similar to the previous questionnaire, but the general question was "Do you think these activities have helped you develop or improve your capabilities?”, to each activity and each capability. The questions had to be answered also on a 5-point Likert scale. In addition, in this questionnaire questions regarding the general satisfaction with the course and the intention to recommend it were included. The level of satisfaction was assessed by one item "What is your degree of satisfaction with the course?”, a 5-point Likert-scale was used. In addition, recommendation was also measured by one item "Would you recommend other students to take this course?", measured with a 5-point Likert scale.

The data collected were computed and analysed using the SPSS 19. The frequency and percentages of the responses to the specific questions were calculated. We used chisquared analysis to analyse whether the personal characteristics of the students influenced some of their responses. Spearman's rho rank-order correlations, which is a non-parametric test that is used to measure the degree of association between two ranked variables (Myers et al., 2010), were used to investigate any significant correlations between the ordinal scales, that is, those which were measured by 5-point Likert scales. The correlations were measured between the objectives that they thought they could achieve developing the different activities, and the capabilities they thought that they had improved with these activities, the general satisfaction of the course and the possibility of recommendation. 


\section{Results and Discussion}

\section{Descriptive analysis}

Table 1 presents the different activities, the objectives assigned to each activity and the degree of opinion about whether these activities can help achieve these objectives ("Can help" column) and if have finally helped to achieve them ("Have helped" column). Students understand activities programmed to be adequate tools for competences development, and they acknowledge these activities have been effective in developing and/or improving the specified competences.

Table 1. Objectives and capabilities that students thought that the activities could help to acquire and which have finally have help to acquire

\begin{tabular}{|c|c|c|c|c|}
\hline Activity & Objectives & Opinion categories & Can help & Have helped \\
\hline \multirow{4}{*}{ Exercises } & \multirow{4}{*}{$\begin{array}{l}\text { Illustrate specific concepts related } \\
\text { to a given topic }\end{array}$} & 2 - Disagree & $1.9 \%$ & $5.8 \%$ \\
\hline & & 3 - Neutral & $11.5 \%$ & $21.2 \%$ \\
\hline & & 4 - Agree & $69.2 \%$ & $61.5 \%$ \\
\hline & & 5 - Strongly agree & $17.3 \%$ & $11.5 \%$ \\
\hline \multirow{12}{*}{ Cases } & \multirow{4}{*}{$\begin{array}{l}\text { Illustrate. Use and apply models of } \\
\text { analysis studied in class }\end{array}$} & 2 - Disagree & $0.0 \%$ & $1.9 \%$ \\
\hline & & 3 - Neutral & $5.8 \%$ & $21.2 \%$ \\
\hline & & 4 - Agree & $65.4 \%$ & $59.6 \%$ \\
\hline & & 5 - Strongly agree & $28.8 \%$ & $17.3 \%$ \\
\hline & \multirow{4}{*}{$\begin{array}{l}\text { Models. Develop diagnosis } \\
\text { capabilities }\end{array}$} & 2 - Disagree & $1.9 \%$ & $3.8 \%$ \\
\hline & & 3 - Neutral & $28.8 \%$ & $30.8 \%$ \\
\hline & & 4 - Agree & $48.1 \%$ & $50.0 \%$ \\
\hline & & 5 - Strongly agree & $21.2 \%$ & $15.4 \%$ \\
\hline & \multirow{4}{*}{$\begin{array}{l}\text { Diagnosis. Develop a systemic } \\
\text { understanding of a given business } \\
\text { situation }\end{array}$} & 2 - Disagree & $5.9 \%$ & $5.8 \%$ \\
\hline & & 3 - Neutral & $21.6 \%$ & $25.0 \%$ \\
\hline & & 4 - Agree & $49.0 \%$ & $48.1 \%$ \\
\hline & & 5 - Strongly agree & $23.5 \%$ & $21.2 \%$ \\
\hline \multirow{8}{*}{$\begin{array}{l}\text { Articles } \\
\text { and } \\
\text { readings }\end{array}$} & \multirow{4}{*}{$\begin{array}{l}\text { Knowledge. Acquire } \\
\text { complementary knowledge about a } \\
\text { given topic }\end{array}$} & 2 - Disagree & $7.7 \%$ & $7.7 \%$ \\
\hline & & 3 - Neutral & $25.0 \%$ & $21.2 \%$ \\
\hline & & 4 - Agree & $44.2 \%$ & $53.8 \%$ \\
\hline & & 5 - Strongly agree & $23.1 \%$ & $17.3 \%$ \\
\hline & \multirow{4}{*}{$\begin{array}{l}\text { Analytical. Develop analytical } \\
\text { capabilities }\end{array}$} & 2 - Disagree & $3.8 \%$ & $3.8 \%$ \\
\hline & & 3 - Neutral & $34.6 \%$ & $46.2 \%$ \\
\hline & & 4 - Agree & $53.8 \%$ & $36.5 \%$ \\
\hline & & 5 - Strongly agree & $7.7 \%$ & $13.5 \%$ \\
\hline \multirow{9}{*}{$\begin{array}{l}\text { Oral } \\
\text { presentati } \\
\text { ons }\end{array}$} & \multirow{5}{*}{$\begin{array}{l}\text { Group work. Be able to work in } \\
\text { work (negotiation, job } \\
\text { coordination) }\end{array}$} & 1 - Strongly disagree & $0.0 \%$ & $1.9 \%$ \\
\hline & & 2 - Disagree & $7.7 \%$ & $9.6 \%$ \\
\hline & & 3 - Neutral & $21.2 \%$ & $19.2 \%$ \\
\hline & & 4 - Agree & $40.4 \%$ & $48.1 \%$ \\
\hline & & 5 - Strongly agree & $30.8 \%$ & $21.2 \%$ \\
\hline & \multirow{4}{*}{$\begin{array}{l}\text { Present Orally. Be able to present } \\
\text { orally to an audience the results of } \\
\text { your work }\end{array}$} & 2 - Disagree & $7.7 \%$ & $5.8 \%$ \\
\hline & & 3 - Neutral & $9.6 \%$ & $25.0 \%$ \\
\hline & & 4 - Agree & $50.0 \%$ & $40.4 \%$ \\
\hline & & 5 - Strongly agree & $32.7 \%$ & $28.8 \%$ \\
\hline \multirow{5}{*}{$\begin{array}{l}\text { Individua } \\
1 \text { mind } \\
\text { map }\end{array}$} & \multirow{5}{*}{$\begin{array}{l}\text { Develop a global understanding of } \\
\text { a specific issue, and the relations } \\
\text { between topics }\end{array}$} & 1 - Strongly disagree & $0.0 \%$ & $9.6 \%$ \\
\hline & & 2 - Disagree & $23.1 \%$ & $15.4 \%$ \\
\hline & & 3 - Neutral & $23.1 \%$ & $21.2 \%$ \\
\hline & & 4 - Agree & $34.6 \%$ & $34.6 \%$ \\
\hline & & 5 - Strongly agree & $19.2 \%$ & $19.2 \%$ \\
\hline
\end{tabular}


Regarding satisfaction and recommendation, which is also other way to measure the satisfaction (Keiningham et al., 2007), in general, students are satisfied (55.8\% satisfied and $25 \%$ strongly satisfied) and will recommend other students to take this course (38.5\% agree and 38.5\% strongly agree). It is worth noting that no student was strongly dissatisfied or strongly disagreed.

\section{Chi-square test for independence}

Given two categorical variables, the chi-squared test of independence determines whether or not there exists a statistical dependence between them, that is, whether the proportions for one variable are different among values of the other variable.

In our case, we analyse whether or not there is an association between sociodemographic characteristics (gender, age, Erasmus or not and student characteristics) and opinion about the objectives that can or have helped achieve each activity.

We conclude that there is no association between the variables under consideration (pvalue $>0.05$ ), except for gender and the opinion that "Articles and readings" can help to achieve the objective "Acquire complementary knowledge about a given topic" (ChiSquare=10.969; Sig. $=0.012$ ). Most women do agree that articles and readings can help increase knowledge (52.8\% do agree and $22.2 \%$ do strongly agree) and a minor percentage is neutral (25\%). However, men's opinion is equally distributed from disagree to strongly agree ( $25 \%$ in each category)

\section{Correlation analysis: Spearman's rho test}

Correlation is a bivariate analysis that measures the strengths of association between two variables. The value of the correlation coefficient varies between +1 and -1 . Specifically, coefficients between 0.10 and 0.29 represent a small association; coefficients between 0.30 and 0.49 represent a medium association; and coefficients above 0.50 represent a large association or relationship (Corder and Formena, 2014). We will focus on Spearm rank correlation. This test does not make any assumptions about data distribution and is the appropriate correlation analysis when the variables are measured on a scale that is at least ordinal (Lehman, 2005; Spearman, 1904).

We will analyse the correlation between the opinion about whether the activities under consideration can help develop or improve certain capabilities before and after carrying them out, and the perception of whether they have finally helped achieve the objectives, and the general satisfaction level and recommendation intentions.

Table 2 shows Rho test for all the variables under consideration. It is worth noting that, regardless of significance, all Rho test values are positive (Rho $>0$ ), indicating a direct positive relationship between variables, that is, they move in the same direction.

Regarding the opinions about whether the different activities have helped achieve the objectives under consideration, significant correlations were found with the opinions they had at the beginning of the course regarding whether they thought they could help $(p<0.05)$. The Rho test shows a large association or relationship for each variable (Rho>0.50), except for "Exercises" can and have helped illustrate specific concepts and "Cases" can and have helped develop diagnosis capabilities, which represent a medium association (Rho between 0.30 and 0.49 ).

In the second block of variables listed in Table 5, the relationship between the opinion about the objectives that the different activities have helped achieve and the satisfaction of the course are presented. We can observed that there is not significative correlation between the general satisfaction of the course and the opinion about whether the 
"Cases" have helped develop diagnosis capabilities, "Articles and readings" have helped develop analytical capabilities and "Oral presentations" have helped being able to work in work (negotiation, job coordination) and being able to present orally to an audience the results of your work ( $p>0.05)$. However, there is a medium association between the level of satisfaction and the opinion about the "Exercises" have helped illustrate specific concepts related to a given topic, "Cases" have helped use and apply models of analysis studied in class", "Articles and readings" have helped acquire complementary knowledge about a given topic, and "Mind map" has helped develop a global understanding of a specific issue, and the relations between topics (Rho between 0.30 and $0.49 ; \mathrm{p}<0.05$ ). Finally, there is a small association between satisfaction and opinion about "Cases" have helped develop diagnosis capabilities (Rho=0.296; $\mathrm{p}<0.05)$.

In the third block of variables in Table 2, the relationship between the opinion about the objectives that the different activities have helped achieve and the probability of recommending other students to take this course are presented. It is worth noting that there is not significative correlation between the possibility of recommending the course and the opinion about whether the "Exercises" have helped illustrate specific concepts related to a given topic, "Articles and readings" have helped develop analytical capabilities, and "Oral presentations" have helped being able to work in work and to present orally to an audience the results of your work ( $>0.05$ ). However, there is a large association between the possibility of recommendation and the opinion of "Articles and readings" have helped acquire complementary knowledge about a given topic (Rho=0.518; $\mathrm{p}<0.05$ ). Oh the other hand, there is a medium association between the possibility of recommendation and the opinion that "Cases" have helped use and apply models of analysis studied in class, develop diagnosis capabilities and develop a systemic understanding of a given business situation, and "Mind maps" have helped develop a global understanding of a specific issue, and the relations between topics (Rho between 0.30 and $0.49 ; \mathrm{p}<0.05$ ).

Finally, it is worth noting that there is a positive and large association between the satisfaction with the course and the probability of recommending it $(\mathrm{Rho}=0.715 ; \mathrm{p}<0$ 005). If a student is satisfied with the course, there would be a high probability of recommending other students to take this course. 
Table 5. Spearman's Rho test

\begin{tabular}{|c|c|c|c|}
\hline & & Rho & $\begin{array}{l}\text { Sig. (2- } \\
\text { tailed) }\end{array}$ \\
\hline Have helped: EXERCISES concepts & Can help: EXERCISES & 0.493 & $0.000 * *$ \\
\hline Have helped: CASES_Illustrate & Can help: CASES Illustrate & 0.601 & $0.000 * *$ \\
\hline Have helped: CASES_models & Can help: CASES models & 0.545 & $0.000 * *$ \\
\hline Have helped: CASES_diagnosis & Can help: CASES diagnosis & 0.401 & $0.004 * *$ \\
\hline $\begin{array}{l}\text { Have helped: ARTICLES AND } \\
\text { READINGS Knowledge }\end{array}$ & $\begin{array}{l}\text { Can help: ARTICLES AND } \\
\text { READINGS Knowledge }\end{array}$ & 0.803 & $0.000 * *$ \\
\hline $\begin{array}{l}\text { Have helped: ARTICLES AND } \\
\text { READINGS_Analytical }\end{array}$ & $\begin{array}{l}\text { Can help: ARTICLES AND } \\
\text { READINGS Analytical }\end{array}$ & 0.600 & $0.000 * *$ \\
\hline Have helped: ORAL PRES_Group work & Can help: ORAL PRES Group work & 0.714 & $0.000 * *$ \\
\hline Have helped: ORAL PRES_oral pres & Can help: ORAL PRES oral pres & 0.663 & $0.000 * *$ \\
\hline Have helped: MIND MAP & Can help: MIND MAP & 0.651 & $0.000 * *$ \\
\hline Have helped: EXERCISES concepts & Satisfaction & 0.364 & $0.008 * *$ \\
\hline Have helped: CASES_Ilustrate & Satisfaction & 0.336 & $0.015^{*}$ \\
\hline Have helped: CASES_models & Satisfaction & 0.296 & $0.033 *$ \\
\hline Have helped: CASES_diagnosis & Satisfaction & 0.263 & 0.060 \\
\hline $\begin{array}{l}\text { Have helped: ARTICLES AND } \\
\text { READINGS Knowledge }\end{array}$ & Satisfaction & 0.438 & $0.001 * *$ \\
\hline $\begin{array}{l}\text { Have helped: ARTICLES } \\
\text { READINGS_Analytical }\end{array}$ & Satisfaction & 0.196 & 0.164 \\
\hline Have helped: ORAL PRES_Group work & Satisfaction & 0.235 & 0.093 \\
\hline Have helped: ORAL PRES_oral pres & Satisfaction & 0.103 & 0.468 \\
\hline Have helped: MIND MAP & Satisfaction & 0.426 & $0.002 * *$ \\
\hline Have helped: EXERCISES concepts & Recommendation & 0.262 & 0.060 \\
\hline Have helped: CASES_Ilustrate & Recommendation & 0.464 & $0.001 * *$ \\
\hline Have helped: CASES_models & Recommendation & 0.307 & $0.027 *$ \\
\hline Have helped: CASES_diagnosis & Recommendation & 0.399 & $0.003 * *$ \\
\hline $\begin{array}{l}\text { Have helped: ARTICLES AND } \\
\text { READINGS_Knowledge }\end{array}$ & Recommendation & 0.518 & $0.000 * *$ \\
\hline $\begin{array}{l}\text { Have helped: ARTICLES AND } \\
\text { READINGS_Analytical }\end{array}$ & Recommendation & 0.259 & 0.064 \\
\hline Have helped: ORAL PRES_Group work & Recommendation & 0.168 & 0.234 \\
\hline Have helped: ORAL PRES_oral pres & Recommendation & 0.027 & 0.851 \\
\hline Have helped: MIND MAP & Recommendation & 0.346 & $0.012 * *$ \\
\hline Satisfaction & Recommendation & 0.715 & $0.000 * *$ \\
\hline
\end{tabular}

*Sig. $<0.05$ (2-tailed)

$* *$ Sig. $<0.01$ (2-tailed)

\section{Conclusions}

As suggested by different authors (Andrews et al., 2012; Boyatzis et al., 2008), embedding competences development in different courses is possible provided it is taken into account when programming the course. Our research shows students agree with this and acknowledge their having generated and/or improved the sought after competences. We conclude that when both professor and students involvement is high, results and satisfaction are positive.

Students understand their investment in the course has effectively helped them grow not only in knowledge, but also in competences development (students think activities can help, they acknowledge activities have helped, they are satisfied). Therefore, probably, one of the reasons for the high degree of satisfaction is the professor's practical approach and students' involvement required for this course. 
This research also suggests female students, prefer reading as a learning strategy for the acquisition of complementary knowledge. In spite of the chi-square test being adequate for this size sample, a future research line could be to analyze a bigger sample and find out whether male or female students show different preferred learning strategies. Another future research line is related to the optimum combination of activities required for the development of specific competences.

\section{References}

Adam, S. (2006). An introduction to learning outcomes: A consideration of the nature, function and position of learning outcomes in the creation of the European Higher Education Area. In E. Froment, J. Kohler, L. Purser, \& L. Wilson (Eds.), EUA Bologna Handbook - Making Bologna Work. Berlin: Raabe Verlag.

Andrews, G., \& Russell, M. (2012). Employability skills development Higher Education. Skills and Work Based Knowledge, 2(1), 33-44.

Boyatzis, R., \& Saatcioglu, A. (2008). A 20-year view of trying to develop emotional, socialand cognitive intelligence competencies in graduate management education. Journal of Management Development, 27(1), 92-108.

Corder, G. W., \& Foreman, D. I. (2014). Nonparametric Statistics: A Step-by-Step Approach. John Wiley \& Sons.

EACEA/Eurydice (2010). New Skills for New Jobs. Policy initiative in the field of education: Short Overview of the current situation in Europe. Bruselas: Eurydice p9.

EACEA/Eurydice (2012). The European Higher Education Area in (2012): Bologna process Implementation Report. Bruselas: P9 Eurydice.

EACEA/Eurydice (2014). Modernisation of Higher Education in Europe: Access, Retention and Employability 2014. Eurydice Report. Luxemburg Publications Office.

Katz, R. L. (1974). Skills of an effective administrator. Harvard Business Review, 51(5), 90-102.

Keiningham, T. L., Cooil, B., Andreassen, T. W., \& Aksoy, L. (2007). A longitudinal examination of net promoter and firm revenue growth. Journal of Marketing, 71(3), 39-51.

Lehman, A. (2005). JMP for basic univariate and multivariate statistics: a step-by-step guide. Cary, NC: SAS Institute.

Myers, J. L., Well, A., \& Lorch, R. F. (2010). Research design and statistical analysis. New York: Routledge.

Parente, D. H., Stephan. J. D., \& Brown. R. C. (2012). Facilitating the acquisition of strategic skills Management Research Review, 35(11), 1004-1028.

Spearman, C. (1904). The proof and measurement of association between two things. The American journal of psychology, 15(1), 72-101. 